\title{
Correction to: Association of Death Anxiety with Spiritual Well-Being and Religious Coping in Older Adults During the COVID-19 Pandemic
}

\author{
Mohammad Rababa ${ }^{1}$ (D A Adai A. Hayajneh ${ }^{1} \cdot$ Wegdan Bani-Issa $^{2}$
}

Published online: 21 January 2021

(C) Springer Science+Business Media, LLC, part of Springer Nature 2021

\section{Correction to: Journal of Religion and Health (2020) https://doi.org/10.1007/s10943-020-01129-x}

The original version of the article was inadvertently published with the error in the author name. The last name of the third author is missing the last letter "a". It should be "Bani-Issa" instead of "Bani-Iss". This has been corrected with this erratum.

Publisher's Note Springer Nature remains neutral with regard to jurisdictional claims in published maps and institutional affiliations.

The original article can be found online at https://doi.org/10.1007/s10943-020-01129-x.

Mohammad Rababa

mjrababa@just.edu.jo

1 Department of Adult Health Nursing, Faculty of Nursing, Jordan University of Science and Technology, Irbid, P.O. Box 3030, 22110, Jordan

2 Department of Nursing, College of Health Sciences, Research Institute for Medical and Health Sciences/Health Promotion Research Group, University of Sharjah, P.O. Box 27272, Sharjah, United Arab Emirates 